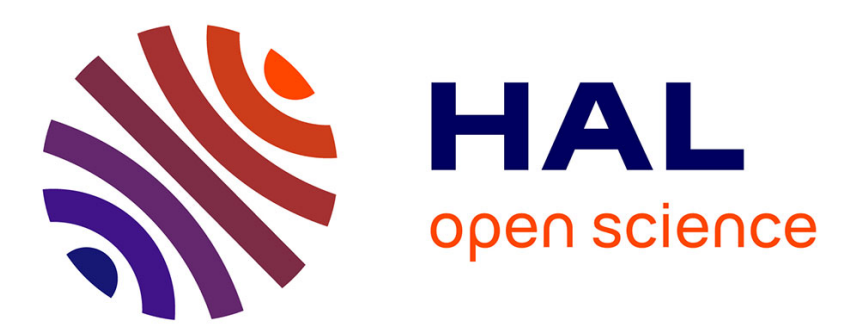

\title{
Evaluation of environmental effects on fatigue crack growth behaviour of a high strength steel in a saline solution with cathodic protection
}

Bertrand Huneau, José Mendez

\section{- To cite this version:}

Bertrand Huneau, José Mendez. Evaluation of environmental effects on fatigue crack growth behaviour of a high strength steel in a saline solution with cathodic protection. International Journal of Fatigue, 2006, 28 (2), pp.124-131. 10.1016/j.ijfatigue.2005.04.011 . hal-01006822

\section{HAL Id: hal-01006822 \\ https://hal.science/hal-01006822}

Submitted on 2 Oct 2017

HAL is a multi-disciplinary open access archive for the deposit and dissemination of scientific research documents, whether they are published or not. The documents may come from teaching and research institutions in France or abroad, or from public or private research centers.
L'archive ouverte pluridisciplinaire $\mathbf{H A L}$, est destinée au dépôt et à la diffusion de documents scientifiques de niveau recherche, publiés ou non, émanant des établissements d'enseignement et de recherche français ou étrangers, des laboratoires publics ou privés. 


\title{
Evaluation of environmental effects on fatigue crack growth behaviour of a high strength steel in a saline solution with cathodic protection
}

\author{
Bertrand Huneau ${ }^{a}$, José Mendez ${ }^{b}$ \\ ${ }^{a}$ Institut de Recherche en Génie Civil et Mécanique, UMR CNRS 6183, Ecole Centrale de Nantes, 1 rue de la Noë, BP. 92101, F-44321 Nantes cedex 3, France \\ ${ }^{b}$ Laboratoire de Mécanique et de Physique des Matériaux, UMR CNRS 6617, ENSMA, Téléport 2, BP.40109, F-86961 Futuroscope Chasseneuil cedex, France
}

\begin{abstract}
Crack growth rates of small fatigue cracks in a high strength steel tested in $3.5 \% \mathrm{NaCl}$ solution with cathodic protection are analysed in the Paris regime through the comparison with the corresponding results obtained in air or in high vacuum. Environmental effects in the saline solution are due to hydrogen produced by cathodic polarisation, which causes intergranular and transgranular brittle fracture surfaces. By comparison to fatigue crack growth rates obtained in air, it could be concluded that hydrogen effects are negligible at low $\Delta K$ and then increase with $\Delta K$. But in fact, when compared to results obtained in a non-active media such as high vacuum, hydrogen effects in the saline solution are very high at low $\Delta K$ and decrease slightly when $\Delta K$ increases. In air, adsorption of the different gaseous species as well as hydrogen effects due to water vapour dissociation strongly enhance crack growth rate compared to vacuum especially for low $\Delta K$. Consequently, a comparison with fatigue crack growth results obtained in air does not allow to quantify properly environmental effects due to another active environment such as the saline solution with cathodic protection considered in the present work.
\end{abstract}

Keywords: Fatigue crack growth; Small cracks; Environmental effects; High strength steel

\section{Introduction}

In most of the studies devoted to fatigue crack growth behaviour of metals in a corrosive environment, ambient air is taken as the reference environment. This choice is justified by the fact that air is the most usual working environment for structural materials. It ensues that the fatigue behaviour of these materials is well documented in this environment, which appears consequently as a natural reference. This is the case in many works [1-4] that have been published on the effects of a saline solution on the Fatigue Crack Growth Rates (FCGRs) of long cracks in structural steels under cathodic protection.

The typical fatigue crack growth behaviour obtained in these conditions, for example by Vosikovsky [1], is schematically represented on Fig. 1. This figure is valid for a constant load ratio and does not account for the

\footnotetext{
* Corresponding author. Tel.: +3324037 6882; fax: +33240372566.

E-mail address: bertrand.huneau@ec-nantes.fr (B. Huneau).
}

strength level of the steel. In the $\Delta K$ range where the curve obeys a Paris law: $\mathrm{d} a / \mathrm{d} N=C \cdot \Delta K^{\mathrm{m}}$, the effect of a saline solution compared to air is generally observed above a critical $\Delta K$ value. This effect is characterised by the higher value of $m$ in the corresponding Paris law. It means that the crack growth rate enhancement as $\Delta K$ increases is stronger in the aqueous solution than in air. This regime is followed by the occurrence of a 'plateau' for which the FCGR in $\mathrm{NaCl}$ with cathodic protection remains nearly constant $(m \approx 0)$. According to Vosikovsky [1], the lower is the frequency, the higher is the FCGR value associated with the plateau. Others authors [2,5] established that this FCGR value also increases when the applied cathodic potential becomes more and more negative. In the region below the plateau, where the difference between the $\mathrm{d} a / \mathrm{d} N$ curves in the aqueous solution and air tends to increase with $\Delta K$, environmental effects are attributed to an embrittlement by hydrogen resulting from water reduction near the crack tip $[1,4]$. This mechanism is associated with brittle fracture surfaces. According to FCGRs curves, two conclusions are generally proposed. Firstly, a critical $\Delta K$ value is required to activate the environment-assisted mechanism due to 




Fig. 1. Schematic fatigue crack growth behaviour of a structural steel in a saline solution with a cathodic potential $(\mathrm{NaCl} / \mathrm{CP})$.

hydrogen. Secondly, the effect of hydrogen increases with $\Delta K$ or with the plastic zone size.

Nevertheless, these interpretations are based on the implicit assumption that environmental effects in air can be neglected. However, it is known that air is a very active environment with regard to fatigue crack growth if the results are compared with those obtained in a high vacuum, in which the action of gaseous species are strongly limited [6]. Consequently, if the comparison with results obtained in air remains useful, from an engineering point of view, it does not allow a good comprehension of environmental effects in saline solutions. This requires a comparison with a truly inert environment.

The present study is devoted to the fatigue crack propagation of natural cracks in a high strength steel cycled in $3.5 \% \mathrm{NaCl}$ solution with cathodic protection. Cathodic protection potential and fatigue test frequency have been selected in relation to the use of this steel in offshore applications (jack-up platforms). Previous work by Huneau and Mendez [7] on the same steel has already shown the respective effects of air and $\mathrm{NaCl}$ solution with cathodic protection on fatigue lifetimes, crack initiation kinetics and damage mechanisms, in comparison to the results obtained in vacuum.

The present work intends to go further in fatigueenvironment interactions by investigating the propagation of self-initiated small cracks. The size of these cracks evolves from 100 to $1000 \mu \mathrm{m}$. They correspond however to the incubation period of long cracks generally considered in fatigue crack propagation studies. Environmental effects are analysed through a comparison with the fatigue behaviour obtained in a high vacuum. Fatigue tests were also performed in air, which is considered here as another active environment.

\section{Material and experimental procedure}

\subsection{Material}

The tested steel denoted SE702 is a member of the Superelso family. This structural high strength steel, manufactured by Industeel (ex Creusot-Loire Industrie), is equivalent of the ASTM A517 Grade Q. The chemical composition is indicated in Table 1 . The mechanical properties of the material were recorded as follows: $0.2 \%$ yield stress $780 \mathrm{MPa}$, ultimate tensile strength $860 \mathrm{MPa}$, elongation 19\%. This quenched and tempered steel exhibits a tempered refined martensite microstructure illustrated in Fig. 2; the prior austenite grain size varies from 10 to $100 \mu \mathrm{m}$. Each grain is composed of various martensite colonies, formed by laths having the same orientation.

\subsection{Experimental procedure}

Cylindrical smooth specimens, with a diameter of $5 \mathrm{~mm}$ and a gauge length of $13 \mathrm{~mm}$, were obtained from a $160 \mathrm{~mm}$ thick sheet, parallel to the rolling direction, at a constant distance of $40 \mathrm{~mm}$ from the initial ingot surface. After machining, the specimens were mechanically polished with $\mathrm{SiC}$ grinding papers then with diamond paste up to $1 \mu \mathrm{m}$ grade.

Fatigue experiments were performed under stress control with a load ratio $R=-1$. Experiments in air (relative humidity $>40 \%)$ and in vacuum $\left(<2 \times 10^{-4} \mathrm{~Pa}\right)$ were performed on a hydraulic machine, at $20 \mathrm{~Hz}$, while the experiments in the $\mathrm{NaCl}$ solution with cathodic protection $(\mathrm{NaCl} / \mathrm{CP})$ were conducted at $0.17 \mathrm{~Hz}$ on an electromechanical equipment. This frequency corresponds to a representative mean value of the swell frequency in the North Sea. Fatigue experiments were also performed in air at $0.17 \mathrm{~Hz}$ in order to estimate frequency effects in this environment and to allow a direct comparison with $\mathrm{NaCl} / \mathrm{CP}$ data. All fatigue tests were conducted at room temperature.

For the experiments in $\mathrm{NaCl} / \mathrm{CP}$, specimens were polarised with a potentiostat by using a three electrodes electrochemical cell [8]. The working electrode was the specimen itself, the counter electrode was made of platinised titanium and the reference electrode was a saturated calomel electrode (SCE). The results presented in this paper were obtained with a cathodic polarisation of

Table 1

Chemical composition of SE702 (wt.\%)

\begin{tabular}{llllllllll}
\hline $\mathrm{C}$ & $\mathrm{Mn}$ & $\mathrm{Si}$ & $\mathrm{Ni}$ & $\mathrm{Cr}$ & $\mathrm{Mo}$ & $\mathrm{Cu}$ & $\mathrm{P}$ & $\mathrm{S}$ & $\mathrm{Fe}$ \\
\hline 0.137 & 1.129 & 0.213 & 2.214 & 0.541 & 0.526 & 0.179 & 0.005 & 0.0009 & Bal. \\
\hline
\end{tabular}




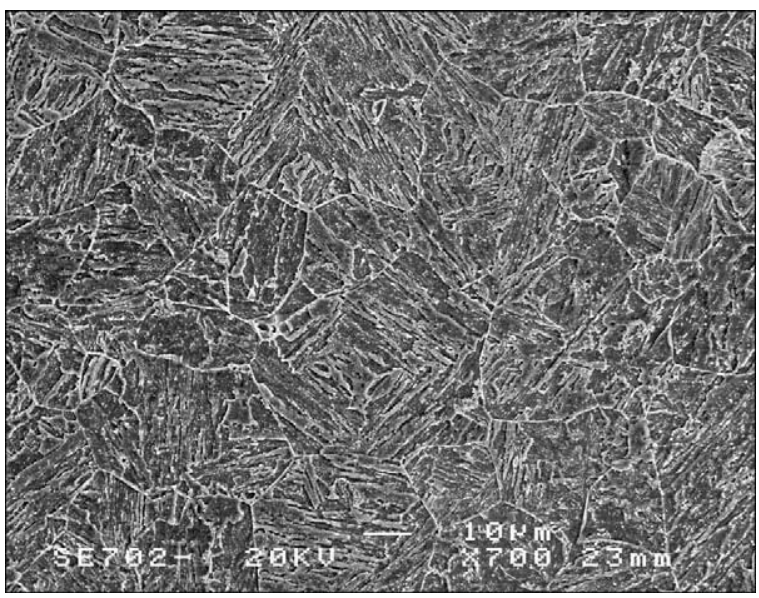

Fig. 2. Microstructure of SE702 steel after chemical etching with nital.

$-1050 \mathrm{mV}$ (SCE) corresponding to an overprotection level. Indeed, according to the Marine Technology Directorate (UK) recommendations [9], the cathodic protection potential of steels with a yield strength greater than $700 \mathrm{MPa}$ should be limited to $-950 \mathrm{mV}(\mathrm{Ag} / \mathrm{AgCl})$ which corresponds to $-905 \mathrm{mV}(\mathrm{SCE})$. The $35 \mathrm{~g} / \mathrm{l} \mathrm{NaCl}$ solution was aerated and neutralised, the $\mathrm{pH}$ being adjusted to 8.1. The specimen is polarised during $20 \mathrm{~h}$ in order to stabilise the cathodic current before starting fatigue experiments. The polarisation is maintained at $-1050 \mathrm{mV}(\mathrm{SCE})$ during fatigue tests.

Specimens gauge lengths and fracture surfaces were observed by scanning electron microscope (SEM) after failure. Propagation mechanisms with regard to the microstructure were analysed for the different environments.

In order to investigate the growth of self-initiated cracks, specimens are first cycled in air at $R=-1$, under $\sigma_{\max }=$ $450 \mathrm{MPa}$ and at $f=20 \mathrm{~Hz}$ until the creation of a surface crack measuring approximately $100 \mu \mathrm{m}$. A regularly interrupted cycling at $R=-1$ under $\sigma_{\max }=450 \mathrm{MPa}$ is then performed in each environment. The surface crack length $L$ was measured after each interruption by direct SEM observations. Before starting the FCGRs monitoring in vacuum and in $\mathrm{NaCl} / \mathrm{CP}$, cracks were propagated of approximately $100 \mu \mathrm{m}$ in length in the considered environment in order to avoid any eventual effect of the initial testing conditions. Thus, FCGRs evaluation starts from a surface crack of approximately $200 \mu \mathrm{m}$.

Crack depth $a$ was estimated from the surface crack length measurements assuming a semi-circular shape of the crack front. This assumption was verified in all the considered environments with a maximum error of $10 \%$ in the range of crack depths from 100 to $1000 \mu \mathrm{m}$, which corresponds to the maximum value considered for FCGRs measurements.

This is illustrated in Fig. 3, which shows a picture of the failure surface of one specimen cycled on specific conditions permitting to establish the crack front geometry. The first marking, from zone 1 to zone 2, was performed by

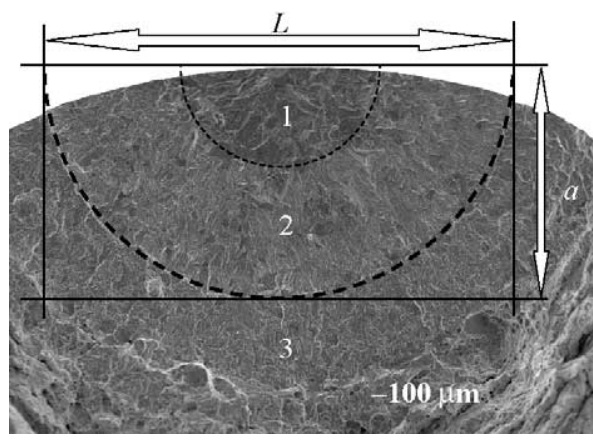

Fig. 3. Semi-circular crack front geometry. Zone $1: \mathrm{NaCl}, \sigma_{\max }=450 \mathrm{MPa}$. Zone 2: air, $\sigma_{\max }=450 \mathrm{MPa}$. Zone 3: air, $\sigma_{\max }=550 \mathrm{MPa}$.

changing the environment from $\mathrm{NaCl} / \mathrm{CP}$ solution to air. The second marking, from zone 2 to zone 3 , was performed in air by changing the applied stress from $\sigma_{\max }=450 \mathrm{MPa}$ to $\sigma_{\max }=550 \mathrm{MPa}$. To prevent rubbing on fracture surfaces, fatigue testes were ended, from the maximum crack depth $(1000 \mu \mathrm{m})$ to failure, with a positive load ratio.

The amplitude of stress intensity factor was evaluated according to ASTM recommendations: $\Delta K=\alpha \sigma_{\max }(\pi a)^{1 / 2}$, with $\sigma_{\max }$ the maximum load applied which is equivalent to the positive part of the stress cycle, and $\alpha$ a geometric factor which can be expressed, according to Carpinteri [10] as a function of $a / D: \alpha=0,643+0,986(a / D)-1,357(a / D)^{2}+$ $4,172(a / D)^{3}$ where $a$ is the depth of crack and $D$ the diameter of the cylindrical fatigue specimens.

This function can be used for cylindrical specimens when crack depth is small compared to the specimen diameter. Its ability to describe the crack growth of Stage II natural cracks as a function of the stress intensity factor, as far as the crack area includes several grains and the crack front geometry is stabilised, was verified in a previous work [11]. These conditions are verified in the present study since the considered cracks are greater than $100 \mu \mathrm{m}$ in depth. These cracks are beyond their early stages of formation in which FCGR is very sensitive to the microstructure. Moreover, the crack size always remains smaller than $\mathrm{D} / 5$.

\section{Results}

\subsection{Fatigue crack growth rates curves}

FCGRs curves established in air and in vacuum at $20 \mathrm{~Hz}$ and in air and in $\mathrm{NaCl} / \mathrm{CP}$ at $0.17 \mathrm{~Hz}$ are plotted in Fig. 4 . For each test conditions, the crack growth evolution obeys a Paris law $\left(\mathrm{d} a / \mathrm{d} N=C . \Delta K^{\mathrm{m}}\right)$. The corresponding $C$ and $m$ values are reported in Table 2. This table also indicates the initial crack depth at which fatigue crack growth tests were started.

The corresponding $\mathrm{d} a / \mathrm{d} N-\Delta K$ results obtained at $20 \mathrm{~Hz}$ in air and in vacuum are in good agreement with the effective Paris laws, $\mathrm{d} a / \mathrm{d} N-\Delta K_{\text {eff }}$, previously determined for long cracks by Hénaff et al. [12] on another high strength 


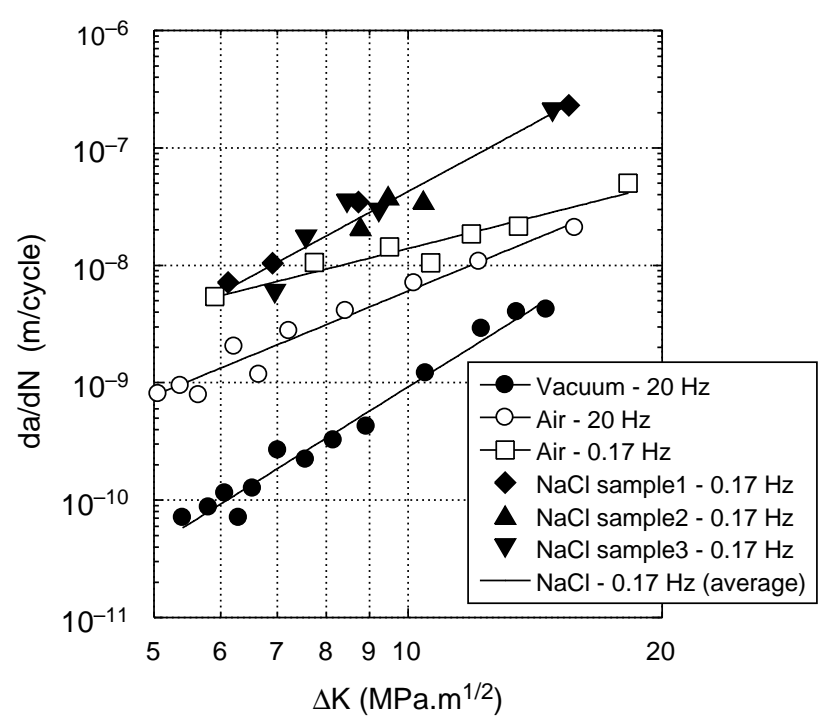

Fig. 4. FCGRs curves in vacuum $(20 \mathrm{~Hz})$, air $(20$ and $0.17 \mathrm{~Hz})$ and $\mathrm{NaCl} / \mathrm{CP}$ $(0.17 \mathrm{~Hz})$.

steel and which expresses FCGRs versus the effective value of $\Delta K, \Delta K_{\text {eff }}$, as defined by Elber [13] to take into account for crack closure. This confirms that crack closure remains limited for such natural small cracks as it has been previously shown by Lindley and Pineau [14] and Nadot et al. [11]. Therefore, even if crack closure has not been directly measured in our specimens it can be considered that the nominal $\Delta K$ value, evaluated by means of the Carpinteri relation reported before, for semi-circular shaped cracks, is very close to the effective value of the stress intensity factor $\Delta K_{\text {eff }}$.

For the tests conducted in $\mathrm{NaCl} / \mathrm{CP}$, three different specimens were used and the corresponding curves are well superimposed. For the conditions investigated, crack growth rates remain below the value corresponding to the plateau frequently observed in long crack $\mathrm{d} a / \mathrm{d} N-\Delta K$ curves as represented in Fig. 1. Indeed, according to Vosikovsky [1], for our experimental conditions this plateau would occur at crack growth rates higher than $10^{-7} \mathrm{~m} /$ cycle. When comparing the results obtained in $\mathrm{NaCl} / \mathrm{CP}$ and in air at the same frequency $(0.17 \mathrm{~Hz})$, the effect of the aqueous environment appears in good agreement with the behaviour described in Fig. 1. At low $\Delta K$, crack growth rates are equivalent in $\mathrm{NaCl} / \mathrm{CP}$ and in $\operatorname{air}(0.17 \mathrm{~Hz})$. Then, when $\Delta K$ increases, the FCGRs enhancement is more pronounced in the saline solution than in air. It corresponds to a higher

Table 2

Initial crack depth $a_{\mathrm{i}}, C$ and $m$ values in the Paris law $\mathrm{d} a / \mathrm{d} N=\mathrm{C} . \Delta \mathrm{K}^{m}$

\begin{tabular}{lllll}
\hline & $\begin{array}{l}\text { Vacuum } \\
(20 \mathrm{~Hz})\end{array}$ & $\begin{array}{l}\text { Air } \\
(20 \mathrm{~Hz})\end{array}$ & $\begin{array}{l}\text { Air } \\
(0.17 \mathrm{~Hz})\end{array}$ & $\begin{array}{l}\mathrm{NaCl} \\
(0.17 \mathrm{~Hz})\end{array}$ \\
\hline ai & 100 & 90 & 120 & 130 \\
$\mathrm{C}$ & $2.9 \times 10^{-14}$ & $6.7 \times 10^{-12}$ & $2.2 \times 10^{-10}$ & $5.5 \times 10^{-12}$ \\
M & 4.5 & 2.9 & 1.8 & 3.9 \\
\hline
\end{tabular}

slope value $(m)$ in $\mathrm{NaCl} / \mathrm{CP}$ than in air. For the final crack depths, or the higher $\Delta K$ values investigated, crack growth rate is ten times higher in $\mathrm{NaCl} / \mathrm{CP}$ than in air.

If the curve obtained in $\mathrm{NaCl} / \mathrm{CP}$ is now compared to the one obtained in vacuum, two main observations can be done. First, there is a marked effect of $\mathrm{NaCl} / \mathrm{CP}$ in particular at low $\Delta K$ values, since crack growth rate is enhanced by a factor 60 compared to vacuum at $\Delta K=6 \mathrm{MPa} \mathrm{m}^{1 / 2}$. Secondly, the slope of the curve obtained in $\mathrm{NaCl} / \mathrm{CP}$ is only slightly lower than the one in vacuum, which means that this enhancement is nearly constant in all the investigated $\Delta K$ range.

The comparison between the results obtained at $20 \mathrm{~Hz}$ in air and in vacuum shows that crack propagation is very sensitive to the gaseous environment especially for earlier stages of propagation. Indeed, the lower is the $\Delta K$, the higher is the difference between FCGRs in these two environments. For $\Delta K=6 \mathrm{MPa} \mathrm{m}^{1 / 2}$ the ratio between crack growth rates in air and vacuum is nearly 15 whereas it is less than 5 for $\Delta K=14 \mathrm{MPa} \mathrm{m}^{1 / 2}$.

A decrease of frequency in air, from 20 to $0.17 \mathrm{~Hz}$, induces an additional crack growth rate enhancement compared to results obtained in vacuum in which frequency effects are assumed to be negligible. In this case the crack growth rate ratio between air and vacuum reach 50 . This frequency effect also decreases as $\Delta K$ increases and becomes negligible around $\Delta K=20 \mathrm{MPa} \mathrm{m}^{1 / 2}$. The maximum ratio between FCGRs in air at $20 \mathrm{~Hz}$ and in air at $0.17 \mathrm{~Hz}$, reached at the lowest $\Delta K$ values, is higher than 3 .

\subsection{Fractographic analysis}

Detailed examinations of the fracture surface morphologies have been performed by SEM on specimens tested on the same conditions: $R=-1, \sigma_{\max }=450 \mathrm{MPa}$. These observations indicate that the crack propagation mode is highly dependent on the environment (Figs. 5-8), but remain almost independent of crack depth along the investigated $\Delta K$ range.

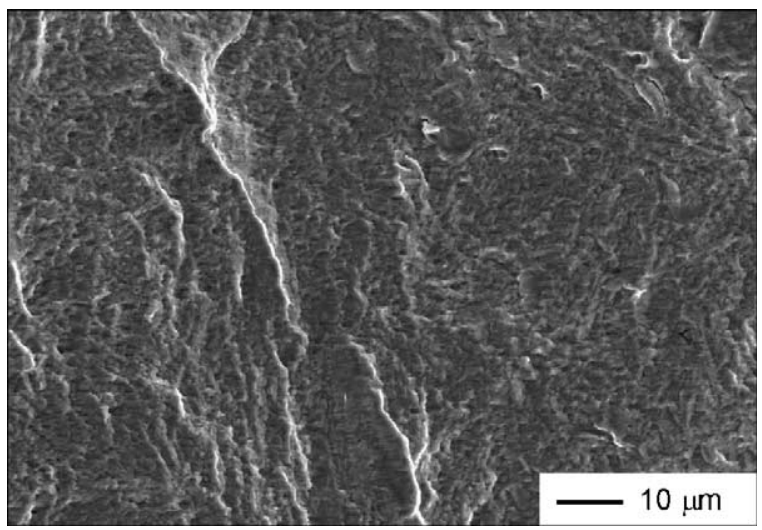

Fig. 5. Typical transgranular fracture surface in vacuum $(20 \mathrm{~Hz})$, $\Delta K \sim 6,5 \mathrm{MPa} \mathrm{m}^{1 / 2}$. 
(a)



(b)

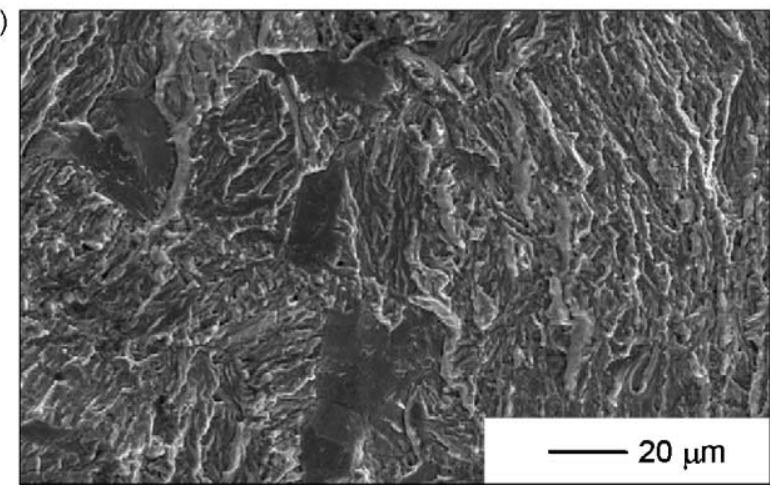

Fig. 6. Fracture surfaces in air (a) $20 \mathrm{~Hz}$, (b) $0.17 \mathrm{~Hz}$ with few intergranular facets, $\Delta K \sim 12 \mathrm{MPa} \mathrm{m}^{1 / 2}$

(a)

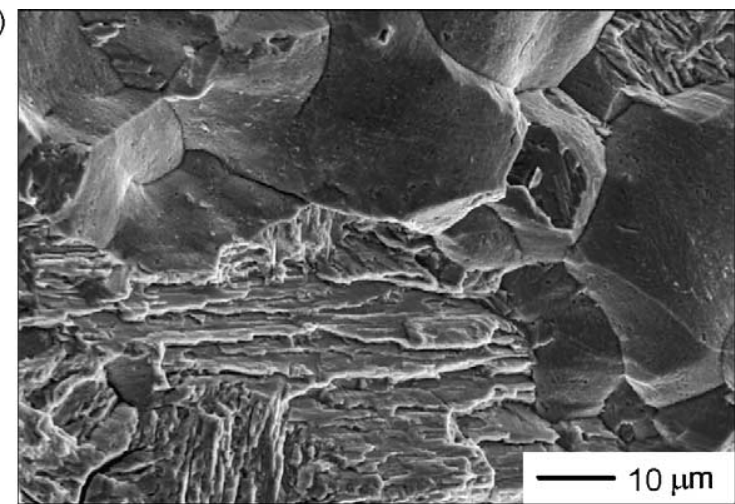

(b)

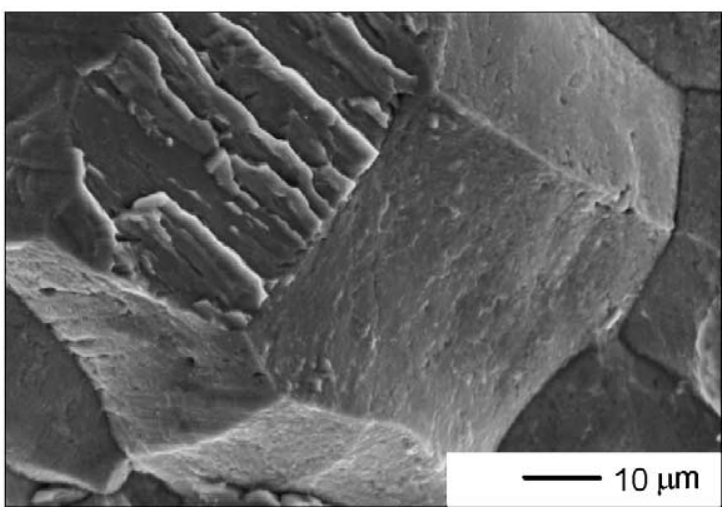

Fig. 7. Fracture surfaces in $\mathrm{NaCl} / \mathrm{CP}(-1050 \mathrm{mV}(\mathrm{SCE}))$ at $0.17 \mathrm{~Hz}$, (a) $\Delta K \sim 9 \mathrm{MPa} \mathrm{m}^{1 / 2}$, (b) at higher magnification $\Delta K \sim 13 \mathrm{MPa} \mathrm{m}^{1 / 2}$. (a)

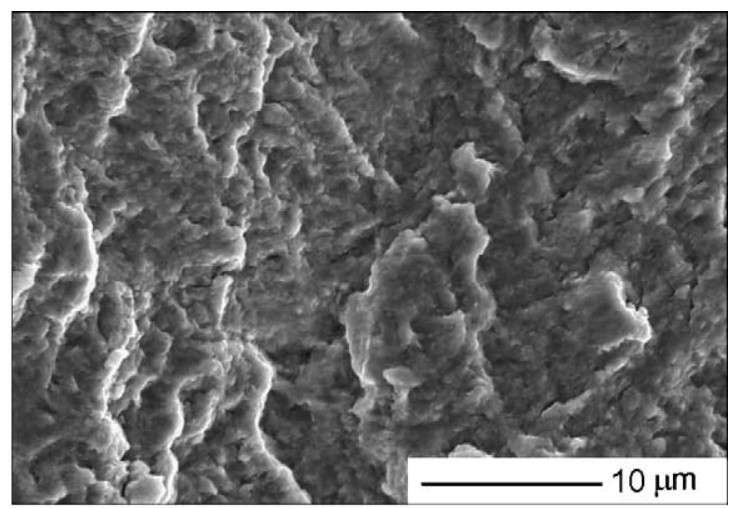

(b)

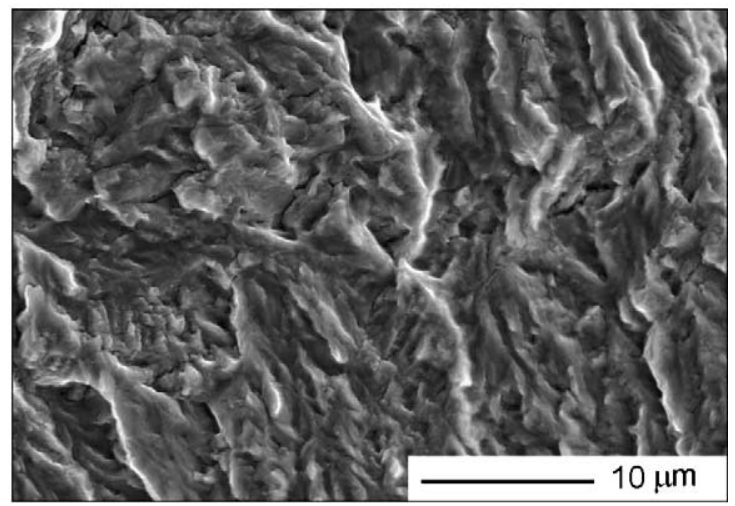

(c)

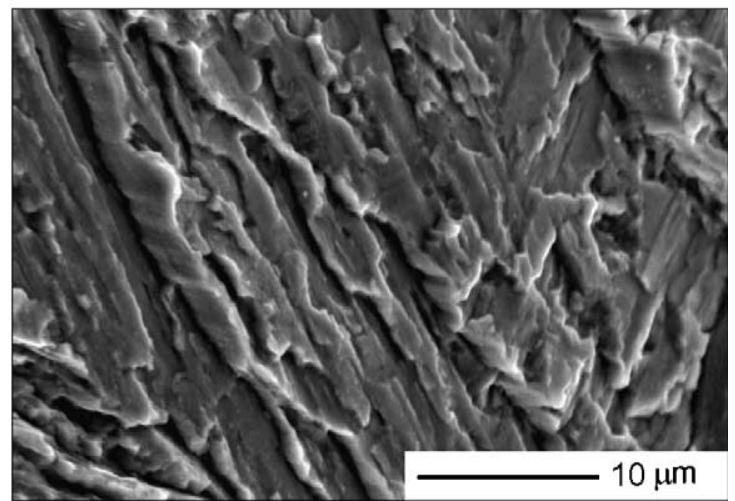

Fig. 8. Transgranular parts of fracture surfaces observed for $\Delta K \sim 11 \mathrm{MPa} \mathrm{m}^{1 / 2}$, (a) in vacuum at $20 \mathrm{HZ}$, (b) in air at $20 \mathrm{~Hz}$ and (c) in $\mathrm{NaCl} / \mathrm{CP}(-1050 \mathrm{mV}(\mathrm{SCE}))$ at $0.17 \mathrm{~Hz}$.

Crack propagation in vacuum is transgranular with respect to the prior austenite grains (Fig. 5). This fracture surface is similar to the ones observed by other authors on comparable steels fatigued in high vacuum $[15,16]$ or inert gases [17,18].

Compared to vacuum, the fracture surfaces in air exhibit a different aspect (Fig. 6). Transgranular parts have a more brittle appearance. Moreover, some brittle intergranular fractures are also seen. These facets represent less than $10 \%$ of the total fracture surface whatever the test frequency. This type of fracture was previously reported by various authors [12,17].

In $\mathrm{NaCl} / \mathrm{CP}$ (Fig. $7 \mathrm{a}$ and $\mathrm{b}$ ), the fracture surface morphology is much more brittle than in air with significant decohesion along prior austenite grain boundaries. 
Intergranular fractures cover approximately 50\% of the whole fracture surfaces. Fig. 7b clearly shows several prior austenite grain boundaries. It is interesting to note on the upper left part of the picture the transgranular brittle fracture due to separations between martensite laths. Very few studies have presented detailed examinations of fracture surfaces in saline solutions with cathodic protection. However some authors have observed and described comparable fracture surfaces on a quenched and tempered steel subjected to stress corrosion cracking in different hydrogenating media as deaerated distilled water, gaseous hydrogen and water vapour $[19,20]$.

Fig. $8 \mathrm{a}-\mathrm{c}$ allow the transgranular fracture areas in the three considered environments to be compared at equivalent magnifications. The embrittlement enhancement from vacuum to air and from air to $\mathrm{NaCl} / \mathrm{CP}$ is clearly shown. The relief appears relatively smooth in vacuum and become rougher in air. In $\mathrm{NaCl} / \mathrm{CP}$, quasi cleavage facets are observed. These distinct geometrical markings are related to the features of martensite laths.

\section{Discussion}

\subsection{Environmental effects in air}

Results in air confirm that this environment is highly active since FCGRs can be amplified by more than one order of magnitude when compared to vacuum. The values of the parameters $m$ and $C$ of the Paris law determined in air at $20 \mathrm{~Hz}$ are comparable to those obtained by Hénaff et al. for long fatigue cracks on another quenched and tempered steel [12]. When compared to results obtained in vacuum, the influence of air (20 and $0.17 \mathrm{~Hz})$ on FCGRs is maximal at low $\Delta K$, and then significantly decreases as the crack grows. At low $\Delta K$ levels, corresponding to low FCGRs, exposure times of the crack tip to the ambient atmosphere are longer than at higher crack growth rates. This allows a maximum action of the gaseous active species at the earliest stages of the crack propagation. In the same way, a frequency decrease, from 20 to $0.17 \mathrm{~Hz}$, leads to an additional increase of FCGRs especially at low $\Delta K$. The slope of the FCGRs curve obtained in air at $0.17 \mathrm{~Hz}$ is inferior to the one obtained at $20 \mathrm{~Hz}$ so that frequency effect becomes almost negligible for the highest $\Delta K$ values. This influence of test frequency is consistent with a time-dependent mechanism since at $0.17 \mathrm{~Hz}$ exposure times are much longer than at $20 \mathrm{~Hz}$ and lead to higher crack growth rates. This result is consistent with our previous work on the same material [7] that showed a reduction in air fatigue lifetimes when the frequency decreases from 20 to $0.17 \mathrm{~Hz}$. This reduction was explained by an acceleration of both initiation and propagation stages. Frequency effects are usually not considered in fatigue studies in air since they are assumed to be negligible, which is probably true for many materials. However, some authors already reported this frequency effect in air on FCGRs, measured with CT specimens, for another high strength steel [21].

Hénaff et al. [12] explain the effect of air by two different processes: the adsorption of water vapour and the action of hydrogen atoms resulting from the dissociation of water vapour as it was initially proposed by Gangloff et al. [22] and Wei et al. [23]. According to Hénaff et al., water vapour adsorption kinetics in ambient air are faster than crack growth rates for fatigue test frequencies commonly used. It means that the contribution of water vapour adsorption remains constant as the crack grows and cannot explain the change in the slope of the FCGRs curve in air compared to vacuum. The significant increase of the air effect at low $\Delta K$ values and at low frequencies confirms an additional contribution of hydrogen resulting from water vapour dissociation. Indeed, as this reaction is time-dependent, a crack growth rate increase reduces the quantity of produced hydrogen. On the other hand, a frequency reduction allows a higher hydrogen production and thus a crack growth rate enhancement. Consequently, the FCGRs curve established at $0.17 \mathrm{~Hz}$ in air is an additional proof of the role of hydrogen in air.

Fracture surfaces in air exhibit mainly transgranular fractures, which only appear slightly more brittle than in vacuum. The propagation mode is not very different in these two environments in spite of great differences in FCGRs. The few intergranular facets observed on fracture surfaces are probably due to the effects of hydrogen from water vapour dissociation. However, as it has been previously pointed out in various studies [12,18], the FCGRs increase in air cannot be directly correlated to the amount of such brittle facets.

\subsection{Environmental effects in $\mathrm{NaCl}$ solution with cathodic protection}

Many authors have reported the deleterious effect of a saline solution with a cathodic protection on FCGRs. There is a general agreement in the literature to attribute this strong effect to hydrogen from water reduction caused by the applied cathodic potential [3]. For long cracks as well as for natural small cracks it is generally accepted that the influence of environment in a saline solution with a cathodic protection starts from a critical crack size or a critical $\Delta K$ level and then increases as the crack grows until FCGRs reach a plateau. For example, Y.Z. Wang et al. [24] monitored natural crack evolution in comparable experimental conditions and concluded that hydrogen accelerates crack propagation as soon as the crack length exceeds $100 \mu \mathrm{m}$. The present study confirms such conclusions as far as the behaviour observed in air is used as the reference.

Our approach, which consists in comparing FCGRs in $\mathrm{NaCl} / \mathrm{CP}$ and in high vacuum, leads to very different conclusions about the contribution of environmental effects in $\mathrm{NaCl} / \mathrm{CP}$ on FCGRs and about the dependence of this contribution on $\Delta K$ level. Indeed, the present results 
indicate that FCGRs are enhanced by two orders of magnitude in $\mathrm{NaCl} / \mathrm{CP}$ compared to vacuum at low $\Delta K$. Moreover, since the FCGRs curves in these two environments are nearly parallel, the environment enhancement in $\mathrm{NaCl} / \mathrm{CP}$ can be considered as little dependent on $\Delta K$.

The fractographic analysis allows the damage mechanisms occurring in the saline solution with cathodic protection to be understood. Fracture surfaces appear completely brittle with sharp separations between either prior austenite grains or martensite laths. Hydrogen due to water reduction is active at all the microstructure interfaces. It should be noted that cathodic protection level $(-1050 \mathrm{mV}(\mathrm{SCE}))$ does not allow the dissolved oxygen to form iron oxides or hydroxides. The role of oxygen can therefore be assumed as negligible in $\mathrm{NaCl} / \mathrm{CP}$. This is confirmed by other studies presenting similar fracture surfaces obtained in hydrogenating media free of oxygen $[19,20]$. In addition, it is interesting to note that the percentage of intergranular facets observed on fracture surfaces remains constant as the crack grows.

In $\mathrm{NaCl} / \mathrm{CP}$, FCGRs curve as well as fracture surface morphologies suggest that cathodic protection produces an amount of hydrogen sufficient to maintain environmental effects close to their maximum in the $\Delta K$ range considered here. In the work of Vosikovsky [1] illustrated in Fig. 1, no effect of the frequency has been noted before the occurrence of the plateau. This means that for small $\Delta K$ levels the production of hydrogen is sufficient to saturate the process zone ahead the crack tip. Since the $\Delta K$ range investigated in the present study remains below the plateau, it is assumed that the frequency would have little or no effect on FCGRs. This assumption is supported by the fact that the protection level that has been used in our work favours a high hydrogen production. However, complementary tests at different frequencies should be necessary to confirm this assertion in the case of natural small cracks.

\subsection{Comparison between $\mathrm{NaCl} / \mathrm{CP}$ and air}

The comparison of the FCGRs obtained in $\mathrm{NaCl} / \mathrm{CP}$ and air with those obtained in vacuum, developed in the previous sections, points out the difficulty in evaluating the environment contribution to FCGRs in $\mathrm{NaCl} / \mathrm{CP}$ only by a comparison with results obtained in air.

At the same test frequency $(0.17 \mathrm{~Hz})$ and for the earliest stages of propagation (or low $\Delta K$ values), FCGRs in air are equal to the ones observed in $\mathrm{NaCl} / \mathrm{CP}$. The results obtained in this study indicate that this equivalence does not mean a lack of influence of $\mathrm{NaCl} / \mathrm{CP}$ on the early propagation stage. Indeed, it is shown that in this domain, ambient air significantly enhances FCGRs when compared to vacuum. Therefore, the correspondence between FCGRs in $\mathrm{NaCl} / \mathrm{CP}$ and in air only reflects a comparable environmentally induced damage at the crack tip in terms of crack growth kinetics. It should be noted that this effect is very high since it increases FCGRs by two orders of magnitude.
But the equivalence of FCGRs in both environments should not be interpreted as the evidence of similar damage processes in these two environments. Indeed, physical mechanisms of damage involved at the crack tip are clearly different as revealed by fracture surfaces analysis. The brittleness of fracture surfaces in $\mathrm{NaCl} / \mathrm{CP}$ compared to air suggests a greater amount of absorbed hydrogen in the saline solution. In air, the additional contribution of water vapour in air, and eventually other active species such as oxygen, is assumed to explain the equivalence in FCGRs obtained in $\mathrm{NaCl} / \mathrm{CP}$ and air at low $\Delta K$.

Finally, it also appears that even if the slope of FCGRs curve is higher in $\mathrm{NaCl} / \mathrm{CP}$ than in air, the effect of the saline environment does not increase as the crack grows. Actually, this effect remains nearly constant for the potential conditions and tests frequencies investigated.

More generally, in aqueous or in gaseous environments, only a comparison with results obtained in a high vacuum or in inert gases allows the environmental contribution on FCGRs to be correctly evaluated.

\section{Summary and conclusions}

Fatigue crack propagation of natural small cracks in the high strength steel SE702 was investigated in different environments. From this study, the following results have been obtained:

- In $3.5 \% \mathrm{NaCl}$ solution at $0.17 \mathrm{~Hz}$, hydrogen produced by cathodic protection strongly enhances FCGRs compared to vacuum. But, contrary to accepted belief based on a comparison with the results obtained in air, the influence of hydrogen does not increase with $\Delta K$. Indeed, the present study shows that hydrogen effects are maximum at low $\Delta K$ levels and decrease slightly when $\Delta K$ or FCGRs increase. Hydrogen generated in $\mathrm{NaCl} / \mathrm{CP}$ induces a marked embrittlement of fracture surfaces with decohesion between either prior austenite grains or martensite laths. This embrittlement is not dependent on $\Delta K$.

- The FCGRs enhancement observed in air compared to vacuum confirms the very active feature of ambient atmosphere on fatigue crack growth processes. Contrary to what is observed in $\mathrm{NaCl} / \mathrm{CP}$, environmental effects in air strongly decrease as $\Delta K$ increases. The strong enhancement of FCGRs in air at low $\Delta K$ is partly attributed to hydrogen resulting from water vapour dissociation. However, even if few intergranular facets are observed, fracture surfaces in air are much more ductile than in $\mathrm{NaCl} / \mathrm{CP}$. The adsorption of gaseous active species such as water vapour represents the other mechanism responsible for FCGRs 
enhancement in air compared to vacuum. A decrease of the fatigue test frequency in air from 20 to $0.17 \mathrm{~Hz}$ increases the contribution of hydrogen and leads to an enhancement of FCGRs especially at low $\Delta K$.

- FCGRs in air can be as elevated as in $\mathrm{NaCl} / \mathrm{CP}$ at the earlier stages of propagation if the tests are performed at the same frequency $(0.17 \mathrm{~Hz})$, even if this equivalence does not correspond to similar damage mechanisms.

- Since air is very active with regard to fatigue crack growth, only the choice of an inert media as reference allows to quantify properly environmental effects due to another active environment such as the saline solution with cathodic protection considered in the present study.

\section{Acknowledgements}

The Région Poitou-Charentes is acknowledged for its financial contribution to the grant of B. Huneau. The authors are also grateful to IFREMER-Brest for financial and technical support, and particularly to D.Choqueuse for his advises concerning the electrochemical experiments. Finally, the authors would like to thank Pr. G. Hénaff for fruitful discussions on environmental effects on fatigue behaviour.

\section{References}

[1] Vosikovsky O. Fatigue crack growth in an X-65 line-pipe steel at low cyclic frequencies in aqueous environments. J Eng Mater Technol, Trans ASME 1975;97(4):298-304.

[2] Truchon M, Rabbe P. Comportement en fatigue-corrosion de différents matériaux métalliques en milieu chloruré. Mémoires et Etudes Scientifiques-Revue de Métallurgie 1983;(3):117-28.

[3] Gangloff RP. Corrosion fatigue crack propagation. In: Gangloff RP, Ives MB, editors. Environment induced cracking of metals. NACE: Houston; 1990. p. 55-109.

[4] Yu J, Brook R, Cole I. The effect of cathodic protection potential on corrosion fatigue crack growth rate of an offshore structural steel. Fatigue Fract Eng Mater Struct 1996;19(8):1019-29.

[5] Maahn E, Noppenau H. The influence of cathodic protection on crack growth from fatigue of steel in seawater. Proceedings of the International Conference Steel in Marines Structures, Paris (France), 1981. p. 1-8.
[6] De Fouquet J, Mendez J, Petit J. Influence de l'environnement. In: Bathias C, Bailon JP, editors. La fatigue des matériaux et des structures. Paris: Hermes; 1997. p. 387-428.

[7] Huneau B, Mendez J. Fatigue behavior of a high strength steel in vacuum, in air and in $3.5 \% \mathrm{NaCl}$ solution under cathodic protection. Mater Sci Eng A 2003;345(1-2):14-22.

[8] Lieurade HP. Essais de fatigue-corrosion-M135. In: Morlet J, Murry J, editors. Etudes et propriétés des métaux-MB2. Paris: Techniques de l'ingénieur; 1998. p. 1-29.

[9] Marine Technology Directorate. Design and operational guidance on cathodic protection of offshore structures, subsea pipelines and pipelines. Publication 90/102; 1990. p. 241-260.

[10] Carpinteri A. Shape change of surface cracks in round bars under cyclic axial loading. Int J Fatigue 1993;15(1):21-6.

[11] Nadot Y, Ranganathan N, Mendez J, Béranger AS. A study of natural cracks initiated on casting defects by crack front marking. Scripta Mater 1997;37(5):549-53.

[12] Hénaff G, Petit J, Bouchet B. Environmental influence on the nearthreshold fatigue crack propagation behaviour of a high-strength steel. Int J Fatigue 1992;14(4):211-8.

[13] Elber W. The significance of fatigue crack closure. Damage tolerance in aircraft structures, ASTM STP 486. Philadelphia (PA): American Society for Testing and Materials; 1971. p. 230-242.

[14] Lindley T, Pineau A. Short crack effects in fracture and fatigue. Revue de Métallurgie, Cahiers d'Informations Tech 1995;92(2):187-201.

[15] Hénaff G. Etude de la tolérance aux dommages en fatigue vibratoire d'un acier type 30NCD16. PhD Thesis, ENSMA, Poitiers, 1991.

[16] Kwon JH. Influence de l'environnement sur le comportement en fatigue d'un acier E460 et d'un alliage léger 7075 près du seuil de fissuration. PhD Thesis, ENSMA, Poitiers, 1985.

[17] Suresh S, Zamiski ZA, Ritchie RO. Oxide-induced closure closure: an explanation for near-threshold fatigue crack growth behavior. Metall Trans A 1981;12A:1435-43.

[18] Liaw PK, Hudak SJ, Donald JK. Influence of gaseous environments on rates of near-treshold fatigue crack propagation in $\mathrm{NiCrMoV}$ steel. Metall Trans A 1982;13A:1633-45.

[19] Simmons GW, Pao PS, Wei RP. Fracture mechanics and surface chemistry studies of subcritical crack growth in AISI 4340 steel. Metall Trans A 1978;9A:1147-58.

[20] Gao M, Lu M, Wei RP. Crack paths and hydrogen-assisted crack growth response in AISI 4340 steel. Metall Trans A 1984;15A: 735-46.

[21] Bignonnet A, Petit J, Zeghloul A. Influence of environment on fatigue crack growth mechanisms. In: Scott P, Cottis RA, editors. Proceedings of the conference on environment assisted fatigue, Sheffield (UK). Bury St. Edmunds (UK): MEP; 1990. p. 205-22.

[22] Gangloff RP, Wei RP. Gaseous hydrogen embrittlement of high strength steels. Metall Trans A 1977;8A:1043-53.

[23] Wei RP, Simmons GW. Recent progress in understanding environment assisted fatigue crack growth. Int J Fract 1981;17(2):235-47.

[24] Wang YZ, Akid R, Miller KJ. The effect of cathodic polarization on corrosion fatigue of a high strength steel in salt water. Fatigue Fract Eng Mater Struct 1995;18(3):293-303. 